Pesq. Vet. Bras. 36(2):83-89, fevereiro 2016 DOI: $10.1590 / \mathrm{S} 0100-736 \mathrm{X} 2016000200004$

\title{
Troponina C na detecção imuno-histoquímica de alterações regressivas precoces no miocárdio de ovinos naturalmente intoxicados por Amaranthus spinosus (Amaranthaceae) ${ }^{1}$
}

\author{
Samay Z.R. Costa ${ }^{2 *}$, Paulo V. Peixoto ${ }^{4}$, Luiz Armando C. Brust ${ }^{3}$, Mariana S. d'Avila², \\ André M. Santos ${ }^{2}$, David Driemeier ${ }^{5}$, Vivian de A. Nogueira ${ }^{6}$ e Ticiana N. França ${ }^{6}$
}

\begin{abstract}
Costa S.Z.R., Peixoto P.V., Brust L.A.C., d'Avila M.S., Santos A.M., Driemeier D., Nogueira V.A. \& França T.N. 2016. [Troponin C in the immunohistochemistry detection of early regressive changes in sheep myocardium naturally poisoned by Amaranthus spinosus (Amaranthaceae).] Troponina C na detecção imuno-histoquímica de alterações regressivas precoces no miocárdio de ovinos naturalmente intoxicados por Amaranthus spinosus (Amaranthaceae). Pesquisa Veterinária Brasileira 36(2):83-89. Curso de Pós-Graduação em Medicina Veterinária, Instituto de Veterinária, Universidade Federal Rural do Rio de Janeiro, BR-465 Km 7, Seropédica, RJ 23890-000, Brazil. E-mail: samayzillmann@gmail.com

Amaranthus spp. are nephrotoxic plants popularly known as "pigweed". In cases of poisoning by these plants, the main histopathological alteration is found in the kidneys as toxic tubular nephrosis; however, in some cases, there may be cardiac changes. ECG changes associated with hyperkalemia have been described in pigs poisoned by Amaranthus retroflexus. Degeneration and necrosis of myocytes have been described in pigs poisoned by $A$. caudatus and sheep poisoned by A. spinosus. There are doubts regarding cardiac changes, since in most cases they are incipient and don't exhibit inflammatory reaction, which can lead to misinterpretation. For this study, paraffin blocks with tissues from a poisoning outbreak by A. spinosus in southeastern Brazil were used. The objective of the study was to detect the presence of incipient regressive changes in the myocardium of sheep poisoned by $A$. spinosus using anti-troponin C antibody-based immunohistochemistry. Fragments of hearts from 8 adult sheep and 2 fetuses naturally poisoned by $A$. spinosus were used. In the immunohistochemistry evaluation of the 8 hearts from the adult sheep there were several groups of myocytes with significant decrease or absence of immunoreactivity for anti-troponin C antibody. In most cases, these same areas on Hematoxylin and Eosin (HE) staining exhibited changes that varied from mild cellular tumefaction to increased eosinophilia, as well as loss of striation, cell lysis and karyolysis, sometimes accompanied by inflammatory infiltrate. In four cases, it was possible to notice that several small groups of myocytes exhibited decreased immunoreactivity corresponding to cells with undetectable or very subtle alterations on HE staining. The hearts of both fetuses did not exhibit areas with loss or decreased immunoreactivity for the anti-troponin $\mathrm{C}$ antibody. The results of this immunohistochemical evaluation confirmed the presence of incipient regressive changes and confirmed the occurrence of well-established necrotic lesions in the myocardium of sheep poisoned by Amaranthus spinosus. There was correspondence between areas where immunostaining for troponin was absent and areas with the most marked lesions obser-
\end{abstract}

\footnotetext{
${ }^{1}$ Recebido em 24 de julho de 2015

Aceito para publicação em 28 de novembro de 2015

Parte da Tese de Doutorado do primeiro autor.

${ }^{2}$ Curso de Pós-Graduação em Medicina Veterinária, Instituto de Veterinária, UFRRJ, BR-465 Km7, Seropédica, RJ 23890-000, Brasil. *Autor para correspondência: samayzillmann@gmail.com

${ }^{3}$ Universidade Estácio de Sá, Estrada Boca do Mato 850, Vargem Pequena, RJ 22783-320, Brasil.
}

\footnotetext{
${ }^{4}$ Departamento Nutrição Animal e Pastagem, Instituto de Zootecnia, Universidade Federal Rural do Rio de Janeiro, BR-465 Km7, Seropédica, RJ 23890-000.

${ }^{5}$ Departamento de Patologia Clínica Veterinária, Faculdade de Veterinária, Universidade Federal do Rio Grande do Sul, Av. Bento Gonçalves 9090, Porto Alegre, RS 95320-000, Brasil

${ }^{6}$ Departamento de Epidemiologia e Saúde Pública, Instituto de Veterinária, UFRRJ, BR-465 Km7, Seropédica, RJ 23890-000.
} 
ved after HE staining. Additionally, the technique was able to detect lesions at a very early stage (myocardial areas with no morphological signs of insult), and demonstrated that the most insulted/injured areas were larger than estimated by observation of HE-stained samples. This study demonstrates the need to better investigate the possible participation of hyperkalemia and other metabolic alterations present in acute renal lesion in the genesis of rapid-onset cardiac lesions, i.e. those not related to vascular lesions caused by long-term uremia.

INDEX TERMS: Poisonous plants, troponin C, immunohistochemistry, sheep, myocardium, plant poisoning, Amaranthus spinosus, Amaranthaceae, pigweed, renal failure.

RESUMO.- Amaranthus spp. são plantas nefrotóxicas popularmente conhecidas como "caruru". Em casos de intoxicação por estas plantas, a principal alteração histopatológica está presente no rim, sob forma de nefrose tubular tóxica, porém em alguns casos pode haver alterações cardíacas. Alterações no eletrocardiograma, compatíveis com quadros de hipercalemia, foram descritas em suínos intoxicados por Amaranthus retroflexus e lesões como degeneração e necrose de miócitos cardíacos descritas em suínos intoxicados por A. caudatus e ovinos intoxicados por A. spinosus. Há dúvidas com relação às alterações cardíacas, que, na maioria dos casos, são incipientes, o que pode levar a erros de interpretação. Para a realização do trabalho foram utilizados blocos parafinados oriundos de um surto natural de intoxicação por A. spinosus no sudeste do Brasil. Esse estudo teve como objetivo detectar a presença de alterações regressivas incipientes no miocárdio de ovinos intoxicados por $A$. spinosus, através da utilização imuno-histoquímica do anticorpo anti-troponina C. Foram utilizados fragmentos de coração de 8 ovinos adultos e 2 fetos, intoxicados naturalmente por A. spinosus. Estes fragmentos foram submetidos à técnica de imuno-histoquímica com a utilização do anticorpo anti-troponina C. Pela avaliação imuno-histoquímica do coração dos oito ovinos adultos observaram-se diversos grupos de miócitos com diminuição significativa ou ausência de imunorreatividade para o anticorpo anti-troponina C; essas áreas correspondiam, em grande parte, aos mesmos grupos de miócitos que apresentavam, pela coloração de Hematoxilina e Eosina (H.E.) alterações que variavam de leve tumefação celular a aumento da eosinofilia, perda de estriação, lise celular e cariólise, ou mais raramente, acompanhadas de infiltrado inflamatório. Em quatro casos foi possível notar que diversos pequenos grupos de miócitos que tinham marcada diminuição de imunorreatividade, correspondiam a células com alterações imperceptíveis ou muito discretas no H.E. Nos corações dos dois fetos não houve áreas com perda ou diminuição de imunorreatividade para o anticorpo anti-troponina C. Os resultados da avaliação imuno-histoquímica confirmaram a presença tanto de alterações regressivas incipientes, quanto ratificaram a ocorrência de lesões necróticas já bem instaladas no miocárdio de ovinos intoxicados por Amaranthus spinosus. Verificou-se correspondência entre as áreas com ausência de imunorreatividade à troponina com as áreas de lesões mais marcadas no H.E.. Adicionalmente, a técnica foi capaz de detectar lesões muito precoces (locais do miocárdio sem sinais morfológicos de agressão), e demonstrou que as áreas agredidas/lesadas eram maiores que o evidenciado no HE. Esse estudo demonstra a necessidade de melhor se in- vestigar a possível participação da hipercalemia e de outras alterações metabólicas presentes na lesão renal aguda, na gênese das lesões cardíacas de rápida instalação, ou seja, aquelas não correlacionadas às lesões vasculares determinadas pela uremia de longa duração.

TERMOS DE INDEXAÇÃ̃O: Plantas tóxicas, troponina C, imuno-histoquímica, miocárdio, ovinos, intoxicação por plantas, Amaranthus spinosus, Amaranthaceae, caruru, insuficiência renal.

\section{INTRODUÇÃO}

Amaranthus spp. são plantas nefrotóxicas popularmente conhecidas como "caruru". A principal alteração histopatológica, na intoxicação por estas plantas, está presente no rim, sob forma de nefrose tubular tóxica, porém em alguns casos pode haver alterações cardíacas relacionadas (Osweiler et al. 1969, Takken \& Connor 1984, Peixoto et al. 2003, Tokarnia et al. 2012).

Alterações no eletrocardiograma, compatíveis com quadros de hipercalemia, foram descritas em suínos intoxicados por Amaranthus retroflexus (Osweiler et al. 1969) e lesões como degeneração e necrose de miócitos cardíacos em suínos intoxicados por $A$. caudatus (Takken \& Connor 1984 ) e em ovinos intoxicados por $A$. spinosus (Peixoto et al. 2003). No entanto, há dúvidas com relação às alterações cardíacas, que, na maioria dos casos, são incipientes ou não apresentam reação inflamatória, o que pode levar a erros de interpretação.

Hipercalemia pode ser uma complicação séria na insuficiência renal em humanos e constitui uma das principais causas de astenia miocárdica e insuficiência cardíaca fatal (Radostits et al. 2002).

Em humanos, não foram encontrados, na literatura consultada, relatos de lesões como degeneração e necrose em células cardíacas associadas à hipercalemia, apenas foram descritas alterações no eletrocardiograma (ECG) (Chawla et al. 1978, Pastor et al. 2001).

A lesão renal aguda pode afetar o coração por diversas vias; através da sobrecarga de líquidos, da uremia não tratada, da hipercalemia (Blake et al. 1996) e da acidose metabólica (Figueras et al. 1976).

Em pacientes humanos há algum tempo já se utiliza dosagem sérica de componentes celulares, como a creatinoquinase e as troponinas, para tentar diagnosticar lesão miocárdica incipiente (Godoy et al. 1998). Isto porque, quando estes pacientes morrem precocemente, muitas vezes apenas a coloração rotineira com hematoxilina e eosina, de fragmentos cardíacos, não é suficiente para evidenciar a necrose das células cardíacas e estabelecer o diagnóstico (Offerman et al. 2000). 
Diversas técnicas imuno-histoquímicas com alta especificidade e sensibilidade têm sido empregadas no intuito de se detectar dano precoce ao miocárdio. A imuno-histoquímica com o anticorpo anti-troponina tem sido utilizada por ser um componente estrutural da célula cardíaca que é liberado na circulação por volta de 3 a 4 horas após a lesão celular (Aires et al. 1999, Jenkins et al. 2010); os miócitos afetados apresentam uma marcação negativa, enquanto os miócitos não-necróticos são positivos para a troponina (Jenkins et al. 2010).

Dessa forma, esse estudo teve como intuito detectar a presença de alterações regressivas incipientes no miocárdio de ovinos intoxicados por A. spinosus, através da utilização imuno-histoquímica com anticorpo anti-troponina C.

\section{MATERIAL E MÉTODOS}

Local. 0 estudo foi realizado no Laboratório de Histopatologia do Setor de Anatomia Patológica, localizado no Anexo I do Instituto de Veterinária da Universidade Federal Rural do Rio de Janeiro, BR-465 Km 7, Seropédica, RJ.

Amostras de tecidos. Fragmentos de coração de 10 ovinos, provenientes do trabalho prévio intitulado "Intoxicação natural por Amaranthus spinosus (Amaranthaceae) em ovinos no sudeste do Brasil" (Peixoto et al. 2003), sendo 8 fêmeas adultas e 2 fetos, intoxicados naturalmente por Amaranthus spinosus no ano de 1997 no município de Paraíba do Sul, no Estado do Rio de Janeiro, fixados em formalina a $10 \%$ e emblocados em parafina, foram submetidos à coloração pela Hematoxilina e Eosina (HE) e à tecnica de imuno-histoquímica com a utilização do anticorpo anti-troponina C. Como controle positivo, foi utilizado fragmento de coração de um ovino intoxicado por monensina.

Imuno-histoquímica. Seções histológicas do coração foram desparafinadas, hidratadas, e incubadas por 30 minutos em peróxido de hidrogênio a $3 \%$ em água destilada, para bloqueio de peroxidases endógenas. Após a lavagem com água destilada, as lâminas ficaram submersas em tampão citrato $\mathrm{pH}$ 6,0 por 15 minutos em banho-maria a $96^{\circ} \mathrm{C}$ para recuperação antigênica. As lâminas foram novamente lavadas em água destilada e seguiu-se o bloqueio de reações inespecíficas com leite desnatado a 5\% (Molico ${ }^{\circledR}$ - Indústria Brasileira) por 30 minutos. Os cortes foram incubados "overnight" com o anticorpo monoclonal anti-troponina $\mathrm{C}$ cardíaca humana (Novocastra, clone 1A2) na proporção de 1:100 $(1 \mu \mathrm{l}$ de anticorpo para $100 \mu \mathrm{l}$ de PBS). Entre o bloqueio de reações inespecíficas e a incubação com o anticorpo as lâminas não foram lavadas. Foi utilizado um sistema de detecção REVEAL polímero-HRP, livre de biotina (Spring), conforme especificado pelo fabricante e como cromógeno a Diaminobenzidina (DAB). Todas as seções foram contra-coradas com hematoxilina de Harris, avaliadas em microscópio óptico (Nikon-Eclipse E200) e fotografadas (Moticam 2500, 5,0 M Pixel).

\section{RESULTADOS}

Pela avaliação imuno-histoquímica do coração dos oito ovinos adultos observaram-se diversos grupos de miócitos com diminuição significativa ou ausência de imunorreatividade para o anticorpo anti-troponina $\mathrm{C}$, essas áreas, via de regra, correspondiam aos mesmos grupos de miócitos no H.E. que apresentavam alterações que variavam de leve tumefação celular a aumento da eosinofilia, perda de estriação, lise celular e cariólise acompanhadas de moderado infiltrado inflamatório misto (Fig.1, 2, 3 e 4). Em dois casos foi possível notar que diversos pequenos grupos de miócitos que apresentavam marcada diminuição de imunorreatividade, correspondiam a células com alterações mui-

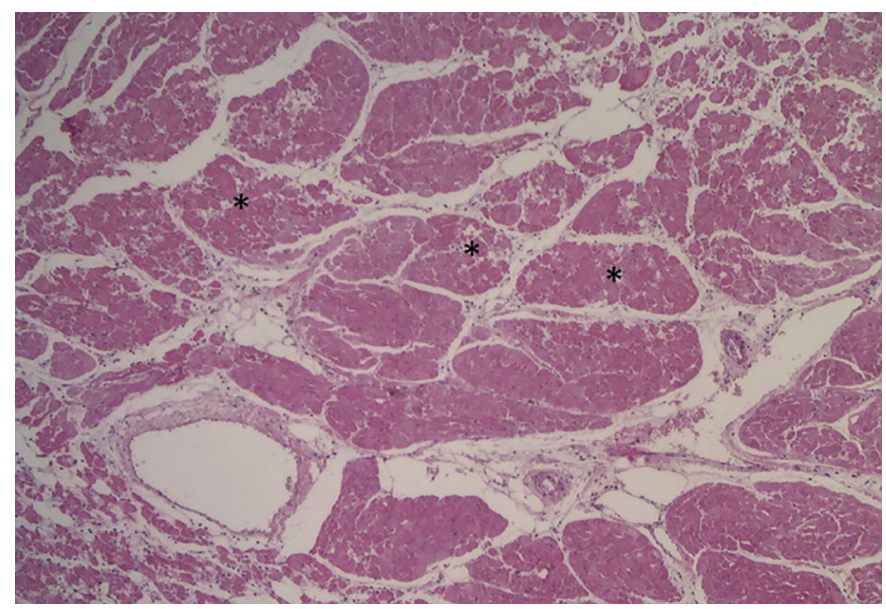

Fig.1. Coração do Ovino 4 intoxicado espontaneamente por A. spinosus. Diversas áreas de evidente necrose de coagulação (asterisco). HE, obj.4x. (SAP 28359)

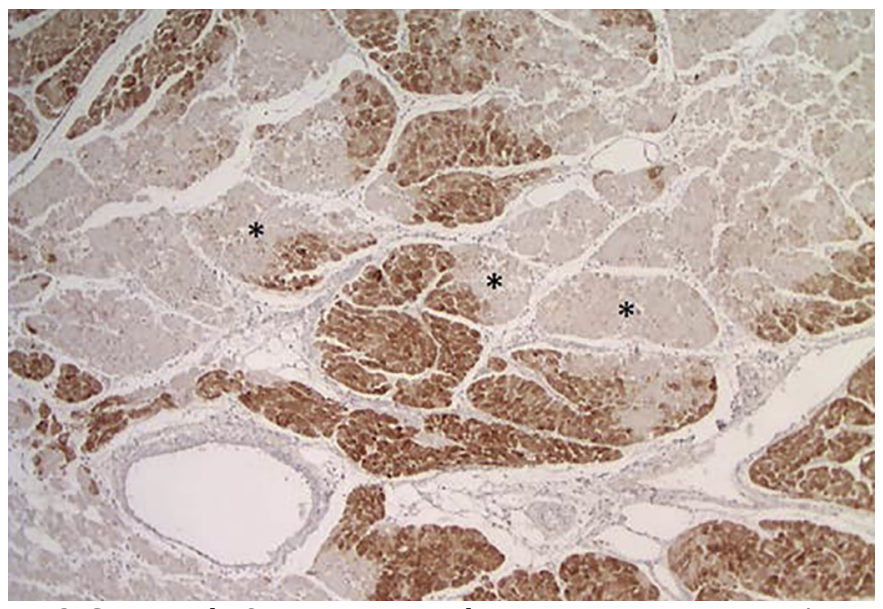

Fig.2. Coração do Ovino 4 intoxicado espontaneamente por $A$. spinosus. Marcada diminuição da imunorreatividade ao anticorpo anti-troponina $C$ nas áreas de necrose observadas na foto anterior (asterisco). HE, obj.4x. (SAP 28359)

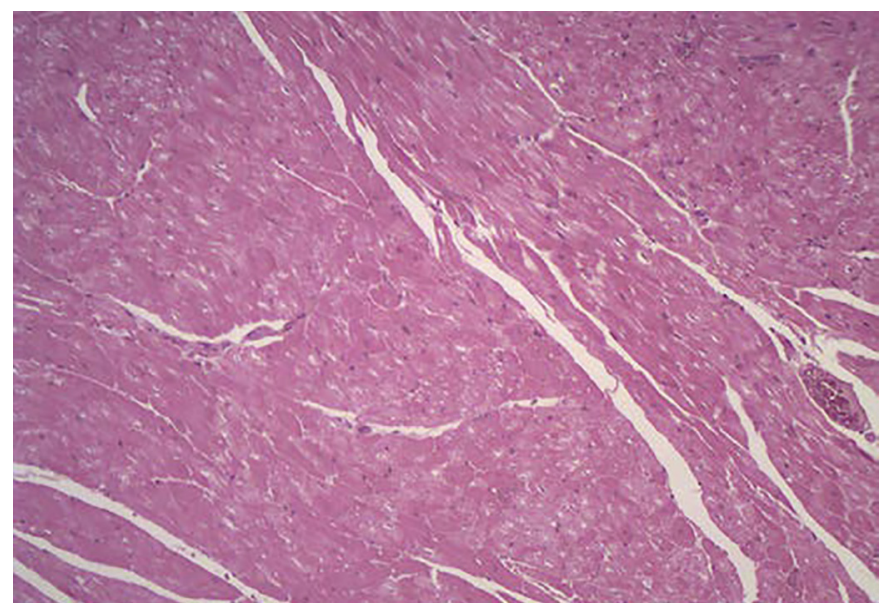

Fig.3. Coração do ovino 7 intoxicado espontaneamente por A. spinosus. Pequenos grupos de fibras cardíacas apresentando discreto aumento de eosinofilia. HE, obj.10x. (SAP 28366A) 


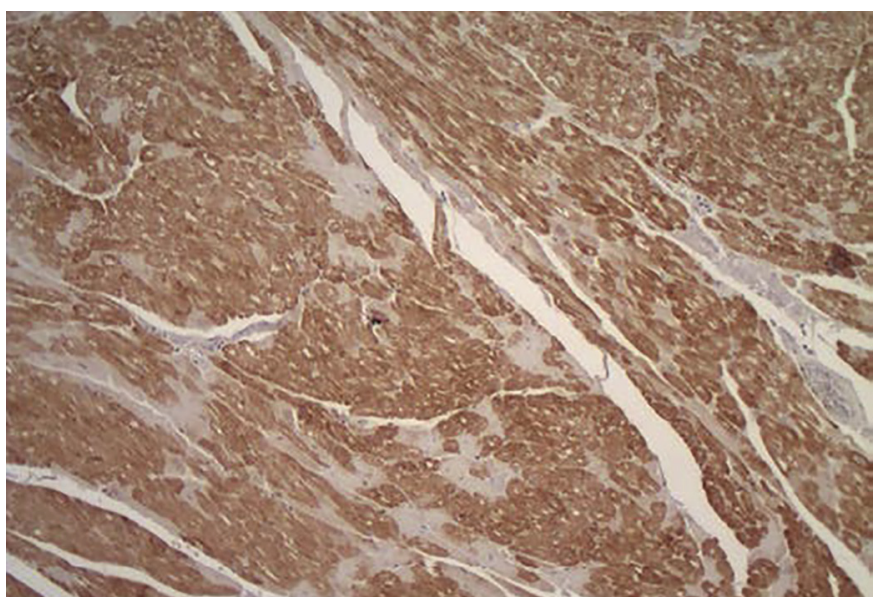

Fig.4. Coração do Ovino 7 intoxicado espontaneamente por A. spinosus. Mesma localização da Figura 3, notar que os pequenos grupos com aumento de eosinofilia correspondem aos miócitos com significativa perda de reatividade. HE, obj.10x. (SAP 28366A)

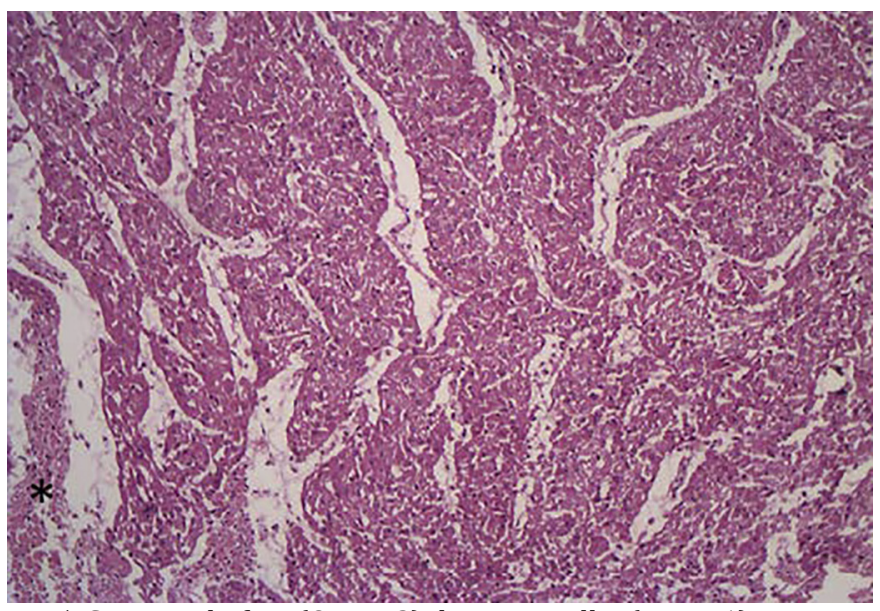

Fig.5. Coração do feto (Ovino 2) de uma ovelha (ovino 1) intoxicada espontaneamente por A. spinosus. Miócitos cardíacos sem alteração. *Tecido conjuntivo. HE, obj.10x. (SAP 28357)

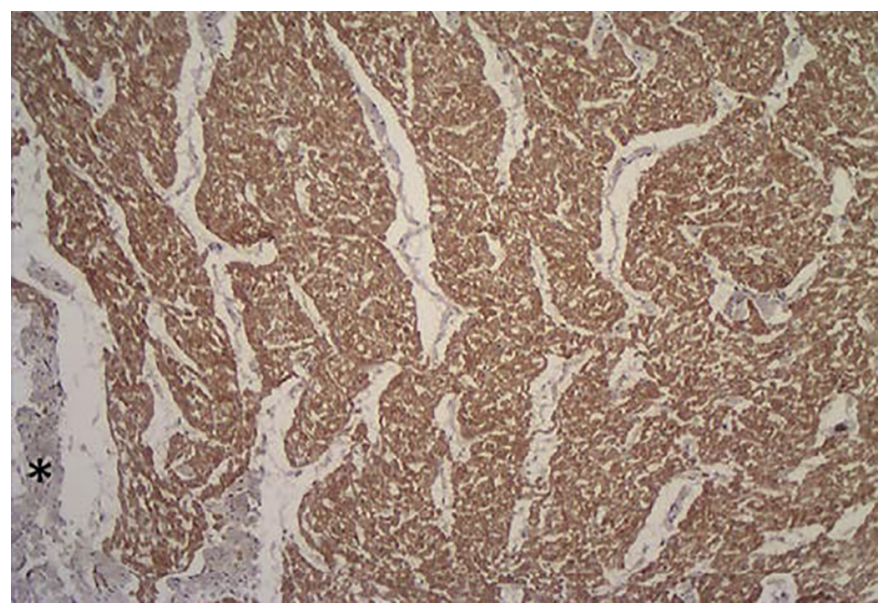

Fig.6. Coração do feto (Ovino 2) de uma ovelha (ovino 1) intoxicada espontaneamente por $A$. spinosus. Imunorreatividade marcada e difusa ao anticorpo ant-troponina C. *Notar o tecido conjuntivo sem marcação. HE, obj.10x. (SAP 28357) to discretas no HE. Além disso, percebeu-se que as áreas que apresentavam perda de tropononina $\mathrm{C}$ eram maiores do que pôde ser notado ao exame histológico de rotina (HE). Nos corações dos fetos não houve áreas com perda ou diminuição de imunorreatividade para o anticorpo anti-troponina C. 0 coração dos fetos e os miócitos cardíacos sem alteração pela HE, dos ovinos intoxicados, serviram como controle interno positivo (Fig.5 e 6). Foi utilizado, também, como controle fragmento do coração de um ovino intoxicado por monensina; houve diminuição significativa da imunorreatividade ao anticorpo anti-troponina $\mathrm{C}$ nas áreas que correspondiam as áreas de necrose observadas pela coloração de HE. Os resultados estão detalhados no Quadro 1.

\section{DISCUSSÃO}

A alteração morfológica que caracteriza as intoxicações por diferentes espécies de Amaranthus sp. é a necrose de coagulação das células epiteliais dos túbulos contorcidos além de alterações extra-renais, muitas vezes associadas à uremia (Buck et al. 1966, Osweiler et al. 1969, Stuart et al. 1975, Armesto et al. 1989, Ferreira et al. 1991, Salles et al. 1991, Lemos et al. 1993, Casteel et al. 1994, Kerr \& Kelch 1998, Peixoto et al. 2003).

Peixoto et al. (2003) descreveram um surto de intoxicação natural por Amaranthus spinosus em ovinos, que apresentavam, além das alterações renais características do quadro de nefrose tubular tóxica, áreas de necrose de coagulação no coração, lesão esta que só havia sido observada por Takken \& Connor (1984) em suínos intoxicados experimentalmente por A. caudatus. Takken \& Connor (1984) descrevem, ainda, que as únicas alterações encontradas foram degeneração miocárdica de leve a severa e quantidades variáveis de líquido no tórax, saco pericárdico e cavidade abdominal. Tanto Peixoto et al. (2003), quanto Takken e Connor (1984) sugerem que a hipercalemia seria a possível causa destas lesões no coração.

Aumento nos níveis de potássio e alterações eletrocardiográficas compatíveis com hipercalemia foram demonstrados por Osweiler et al. (1969) em suínos intoxicados experimentalmente por $A$. retroflexus, que apresentavam nefrose tóxica, porém não havia lesão detectável em células cardíacas.

Apesar de descrever moderada hialinização de arteríolas do pulmão e do coração de bovinos intoxicados por Amaranthus sp., Stuart et al. (1975) não relatam alterações degenerativas/necróticas nos miócitos cardíacos, enquanto que no coração de parte dos ovinos deste estudo existiam áreas de necrose evidente, porém não há, em nenhum dos casos, alterações, mesmo que discretas nos vasos do coração.

Neste estudo avaliaram-se através da técnica de imunohistoquímica, utilizando-se o anticorpo anti-troponina C, fragmentos de coração dos ovinos intoxicados por $\mathrm{A}$. spinosus do estudo realizado por Peixoto et al. (2003), com o objetivo de confirmar as lesões regressivas e detectar a presença e amplitude de alterações regressivas incipientes ou não perceptíveis no miocárdio desses animais pela técnica de rotina (HE). 
Quadro 1. Alterações histológicas evidenciadas pela HE e resultado da imuno-histoquímica com o anticorpo anti-troponina C no miocárdio de ovinos intoxicados naturalmente por $A$. spinosus

\begin{tabular}{|c|c|}
\hline Ovino/SAP & HE \\
\hline $\begin{array}{l}\text { Ovino } 1 \\
(\text { SAP 28356) }\end{array}$ & $\begin{array}{l}\text { Pequenos grupos de cardiomiócitos que apresentavam alterações } \\
\text { como perda da estriação e discreto aumento da eosinofilia, algumas } \\
\text { células apresentavam o citoplasma com aspecto homogêneo. }\end{array}$ \\
\hline $\begin{array}{l}\text { Ovino } 2 \\
\text { (SAP 28357) } \\
\quad \text { Feto }\end{array}$ & $\begin{array}{l}\text { Sem sinais de alterações nos cardiomiócitos perceptíveis nos cortes } \\
\text { corados pela HE. }\end{array}$ \\
\hline $\begin{array}{l}\text { Ovino } 3 \\
\text { (SAP 28358) }\end{array}$ & $\begin{array}{l}\text { Fibras individuais de cardiomiócitos com apenas leve aumento da } \\
\text { eosinofilia. }\end{array}$ \\
\hline $\begin{array}{l}\text { Ovino } 4 \\
\text { (SAP 28359) }\end{array}$ & $\begin{array}{l}\text { Extensas áreas com aumento da eosinofilia, perda de estriação, } \\
\text { citoplasma de aspecto homogêneo e vítreo, lise celular, cariólise e } \\
\text { desaparecimento do núcleo, além de infiltrado inflamatório misto. }\end{array}$ \\
\hline
\end{tabular}

Ovino 5 Grupos de miócitos cardíacos tumefeitos, com perda de estriação

(SAP 28360) e sem infiltrado inflamatório nos cortes corados pela HE.

Ovino 6 Fragmento 1 - Áreas de necrose cardíaca, as células destas áreas

(SAP 28365) apresentavam perda de estriação, citoplasma de aspecto homogêneo e vítreo, fragmentação celular, perda dos núcleos e moderado infiltrado inflamatório misto. Havia ainda, pequenos grupos de cardiomiócitos com apenas discretas alterações como tumefação celular.

Fragmento 2 e 3 - Grupos de miócitos cardíacos com perda de estriação e citoplasma de aspecto homogêneo.

Ovino 7 Pequenos grupos de cardiomiócitos que exibiam apenas leve au(SAP 28366 A) mento da eosinofilia e por vezes perda de estriação e citoplasma de aspecto homogêneo.

Ovino 9 Fragmento 1 - Pequena área de necrose com moderado infiltrado (SAP 28510) inflamatório misto. Grupos de cardiomiócitos que apresentavam alterações extremamente discretas e até mesmo imperceptíveis no HE.

Fragmento 2 - Área de necrose com moderado infiltrado inflamatório misto.

Fragmento 3 - Grupos de cardiomiócitos que apresentavam discreto aumento da eosinofilia, perda de estriação, citoplasma de aspecto homogêneo e fragmentação de algumas células, sem infiltrado inflamatório.

Ovino 10 Áreas de necrose de cardiomiócitos, as células perderam as es-

(SAP 28513) triações, o citoplasma tinha aspecto vítreo, havia fragmentação de algumas células e moderado infiltrado inflamatório misto. Em outros locais havia apenas uma discreta tumefação celular e aspecto homogêneo do citoplasma dos miócitos cardíacos.

Ovino Acentuada hipereosinofilia em diversos cardiomiócitos acompa-

Controle nhada de marcado infiltrado inflamatório composto predominantemente por macrófagos e poucos linfócitos e plasmócitos, havia ainda picnose, cariólise e lise celular.

As troponinas cardíacas T e I têm sido utilizadas como marcadores séricos para demonstrar lesões cardíacas em seres humanos (Babuin \& Jaffe 2005), devido ao aumento das concentrações séricas 4 a 6 horas após lesão ou necrose aguda do miocárdio (Nelson \& Couto 2006, Jenkins et al. 2010). Não há uma utilidade clínica na dosagem sérica da troponina $\mathrm{C}$, uma vez que o músculo cardíaco e o músculo liso partilham a mesma isoforma (Martins 2009).

Em estudos imuno-histoquímicos no coração de seres humanos que morreram por infarto do miocárdio, asfixia, trauma múltiplo e causas naturais (com exceção de infarto do miocárdio), verificou-se em miócitos não lesados reatividade difusa e acentuada à troponina $\mathrm{C}$ em $86 \%$ dos casos, nas áreas de infarto a marcação era fraca e por vezes ausente. Por outro lado a imunorreatividade à troponina
Numerosas pequenas áreas com fraca ou ausência de imunorreatitividade ao anticorpo anti-troponina $C$ entremeadas por células que apresentavam forte coloração.

A reatividade ao anticorpo anti-troponina C foi marcada e difusa, não foram observadas áreas com perda ou diminuição de marcação.

Em algumas áreas havia fibras individuais com marcada diminuição da imunorreatividade ao anticorpo anti-troponina $\mathrm{C}$.

Havia pequenas e extensas áreas de significativa diminuição de reatividade ao anticorpo anti-troponina $\mathrm{C}$, passando por áreas sem marcação. A avaliação imuno-histoquímica demonstrou uma lesão maior e mais significativa do que a observada nos cortes corados pela HE.

Inúmeras pequenas áreas com drástica diminuição ou até mesmo perda completa da imunorreatividade ao anticorpo anti-troponina $\mathrm{C}$. Fragmento 1 - Extensas áreas com ausência de imunorreatividade ao anticorpo anti-troponina C. Ainda neste mesmo fragmento, havia algumas áreas com importante diminuição da reatividade. Neste caso, também foi possível identificar que a lesão cardíaca era maior e mais significativa do que a coloração apenas pela HE permitia identificar.

Fragmento 2 e 3 - Extensas áreas com significativa perda de reatividade entremeadas por cardiomiócitos indiviuais que apresentavam forte marcação.

Algumas áreas com significativa perda de marcação, passando por locais com ausência de reatividade.

Fragmento 1 - Pequena área com ausência de imunorreatividade. Havia ainda algumas pequenas áreas com significativa diminuição da reatividade.

Fragmento 2 - Uma área focalmente extensa com ausência de imunorreatividade.

Fragmento 3 - Áreas com marcada diminuição da reatividade.

Áreas com ausência de imunorreatividade e alguns outros locais com significativa perda de reatividade ao anticorpo anti-troponina C.

Áreas com acentuada depleção na imunomarcação de fibras cardíacas em meio a outras com expressão normal para troponina C.

T, nos miócitos saudáveis, foi menos intensa ( $46 \%$ dos casos) (Martínez-Díaz et al. 2005). No presente estudo também havia imunorreatividade intensa e difusa no coração dos dois fetos e nos miócitos cardíacos que não apresentavam lesão nos cortes corados pela H.E., o que serviu como controle interno positivo para o anticorpo anti-troponina C.

Análises bioquímicas, entre elas potássio, ureia, creatinina, sódio, cloro, magnésio, fósforo e troponinas I e T, do sangue de bezerros com diarreia neonatal, demonstraram marcado distúrbio hidroeletrolítico (hipercalemia, hiponatremia, hipocloremia, hipermagnesemia e hiperfosfatemia), além de um provável quadro de insuficiência renal devido aos altos valores de ureia e creatinina e proteinúria. Foram realizados eletrocardiogramas nos bezerros hiper- 
calêmicos e com diarreia, que comparados ao eletrocardiograma dos animais controle, apresentaram um marcado aumento da amplitude e da duração do complexo QRS e da onda T. Apesar das alterações eletrolíticas e eletrocardiográficas, não foram detectados aumentos nos níveis séricos de troponina. Todos os animais foram tratados após os primeiros exames (Özkan et al. 2011). Acreditamos que as concentrações séricas de troponina poderiam ainda não estar aumentadas devido ao tempo de evolução da doença, provavelmente se os animais não fossem tratados e morressem com este quadro de marcada alteração eletrolítica, principalmente pela hipercalemia e insuficiência renal aguda, lesões cardíacas com consequente aumento das troponinas poderiam ocorrer.

Como observado em outros estudos relacionados a outras causas de lesão cardíaca (Martínez-Díaz et al. 2005, Pavarini et al. 2012), as áreas que apresentavam marcada necrose coagulativa no H.E. no miocárdio dos ovinos intoxicados, correlacionavam-se com a drástica diminuição de imunorreatividade e, por vezes, ausência de reatividade ao anticorpo anti-troponina C. Foi possível estabelecer estreita relação das áreas onde não havia marcação pelo anticorpo com as áreas de necrose mais evidentes que estavam presentes no miocárdio de quatro ovinos deste estudo.

Outra importante observação é que em quatro casos (Ovinos 4, 6, 7 e 10) identificou-se que as áreas com marcada diminuição da expressão imuno-histoquímica da troponina $C$ eram maiores e mais significativas do que os grupos de cardiomiócitos que apresentavam, ao menos, algum grau de alteração no HE. Este achado imuno-histoquímico foi observado, inclusive, em miócitos cardíacos que estavam apenas tumefeitos. Esta redução na marcação provavelmente está relacionada ao aumento nos níveis séricos das troponinas cardíacas que ocorre mesmo a partir de danos reversíveis nos cardiomiócitos como descrito em seres humanos (Lazzeri et al. 2008).

Em muitas áreas do miocárdio dos ovinos foi observada uma marcada diminuição e até ausência de reatividade ao anticorpo anti-troponina $\mathrm{C}$ em locais onde as alterações regressivas eram incipientes em cortes corados pela H.E.

Em pelo menos metade dos animais as alterações histológicas cardíacas foram mais evidentes no presente estudo imuno-histoquímico, do que as descritas por Peixoto et al. (2003). Provavelmente esta diferença se deve ao fato de que lesões muito discretas e incipientes, que por vezes poderiam ser confundidas até mesmo com artefatos, foram mais facilmente visualizadas e identificadas efetivamente como lesões devido à comparação do H.E com a imuno-histoquímica, o que reforça a importância da utilização da técnica na avaliação da real gravidade da lesão cardíaca.

Estes achados corroboram com o observado por outros autores (Ribeiro-Silva et al. 2002, Jenkins et al. 2010, Carretón et al. 2012) em que alterações regressivas extremamente precoces podem ser identificadas através da técnica de imuno-histoquímica utilizando-se o anticorpo anti-troponina $\mathrm{C}$ e que as lesões cardíacas podem ser maiores e mais significativas do que, muitas vezes, é possível avaliar apenas pela coloração de rotina.

Peixoto et al. (2003) ressaltam que não há evidências de lesões determinadas diretamente pela planta nos fetos. É possível que o princípio tóxico de Amaranthus sp. não atravesse a barreira placentária, uma vez que a placenta de ruminantes é do tipo sindesmocorial o que impede a passagem de anticorpos e outras substâncias para o feto por via transplacentária durante a gestação (Tizard 2014). 0 achado de corpúsculos de choque nos vasos de alguns fetos (Peixoto et al. 2003) e a imunorreatividade de forma intensa e difusa para o anticorpo anti-troponina C no coração dos fetos analisados reforçam esta hipótese.

De todas as estruturas cardíacas, apenas os cardiomiócitos expressaram reatividade para o anticorpo anti-troponina C. Tunca et al. (2008) obtiveram resultados semelhantes neste ponto, porém alguns macrófagos e neutrófilos contendo substâncias necróticas exibiram intensa reatividade citoplasmática para o anticorpo anti-troponina I. No presente estudo, nas áreas de necrose onde havia infiltrado inflamatório, não foi observada reatividade das células inflamatórias ao anticorpo anti-troponina $\mathrm{C}$.

A variação da intensidade da marcação do anticorpo anti-troponina C, observada no presente estudo, talvez possa estar relacionada ao fato de que nas primeiras horas após a lesão (4-6 horas) ocorre a liberação de uma pequena quantidade de troponina, que provém do reservatório citosólico e o pico da concentração sanguínea é verificado 48-72 horas após a lesão, correspondendo à troponina do reservatório estrutural, que começa a ser liberada para o plasma graças à destruição das miofibrilas, quando da necrose dos miocardiócitos (Martins 2009).

Aumento nos valores de troponina em pacientes em estágio final de insuficiência renal tem sido descrito (Freda et al. 2002, Lazzeri et al. 2008). Os autores têm levantado hipóteses como aumento da massa ventricular esquerda, dificuldade de excreção renal da troponina, reexpressão da isoforma cardíaca da troponina $\mathrm{T}$ no músculo esquelético em pacientes com miopatia urêmica, maior propensão de sustentar repetidos episódios de micro-infartos clinicamente silenciosos, porém o real motivo permanece desconhecido. Na literatura consultada, não foram encontrados trabalhos que estudassem uma possível correlação entre a hipercalemia ou outros distúrbios eletrolíticos da insuficiência renal com alterações morfológicas do coração ou mesmo com os aumentos nas concentrações das troponinas cardíacas.

Em humanos já se sabe que quadros agudos de insuficiência renal podem levar a desordens cardíacas agudas (síndrome renocárdica aguda - tipo 3) (Ronco et al. 2008), porém pouco se sabe sobre estas associações em animais, principalmente em ruminantes. É possível que nos animais, assim como em humanos as alterações relacionadas com a insuficiência renal aguda, como, por exemplo, a hipercalemia, a acidose metabólica e a ativação da inflamação e da apoptose a nível cardíaco, possa estar envolvida com as alterações no eletrocardiograma descritas por Osweiler et al. (1969) e com a presença das alterações histológicas observadas por Takken \& Connor (1984), Peixoto et al. (2003) e no presente estudo.

Os resultados da avaliação imuno-histoquímica confirmaram a presença tanto de alterações regressivas incipien- 
tes, quanto ratificaram a ocorrência de lesões necróticas já bem instaladas no miocárdio de ovinos intoxicados por Amaranthus spinosus. Esse estudo demonstra necessidade de melhor investigar a possível participação da hipercalemia e de outras alterações metabólicas presentes na lesão renal aguda, na gênese das lesões cardíacas de rápida instalação, ou seja, àquelas não correlacionadas às lesões vasculares determinadas pela uremia de longa duração.

Agradecimentos.- Ao CNPq e à CAPES pelo suporte financeiro.

\section{REFERÊNCIAS}

Aires M.M. 1999. Fisiologia. $2^{\underline{a}}$ ed. Guanabara Koogan, Rio de Janeiro. 934p.

Armesto R.R., Grande H.A., Baroni A.C., Baroni E.E. \& Boggio J. 1989. Intoxicación por Amaranthus quitensis em vaquillonas holando argentino. Vet. Argent. 6(60):692-700.

Babuin L. \& Jaffe A.S. 2005. Troponin: the biomarker of choice for the detection of cardiac injury. Can. Med. Assoc. J. 173(10):1191-1202.

Blake P., Hasegawa Y., Khosla M.C., Fouad-Tarazi F., Sakura N. \& Paganini E.P. 1996. Isolation of "myocardial depressant factor(s)" from the ultrafiltrate of heart failure patients with acute renal failure. ASAIO J. 42:911-915.

Buck W.B., Preston K.S. \& Abel M. 1966. Common weeds as a cause of perirenal edema in swine. Iowa State Univ. Vet. 27:105-108.

Carretón E., Grandi G., Morchón R., Simón F., Passeri B., Cantoni A.M., Kramer L. \& Montaya-Alonso J.A. 2012. Myocardial damage in dogs affected by heartworm disease (Dirofilaria immits): Immunohistochemical study of cardiac myoglobin and troponin I in naturally infected dogs. Vet. Parasitol. 189:390-393.

Casteel S.W., Johnson G.C., Miller M.A., Chudomelka H.J., Cupps D.E., Haskins H.E. \& Gosser H.S. 1994. Amaranthus retroflexus (redroot pigweed) poisoning in cattle. J.Amer. Vet. Med. Assoc. 204(7):1068-1070.

Chawla K.K., Cruz J., Kremer N.E. \& Towne W.D. 1978. Electrocardiographic changes simulating acute myocardial infarction caused by hyperkalemia: Report of a patient with normal coronary arteriograms. Am. Hosp. J. 95(5):637-640.

Ferreira J.L.M., Riet-Correa F., Schild A.L. \& Méndez M.C. 1991. Intoxicação por Amaranthus spp (Amaranthaceae) em bovinos no Rio Grande do Sul. Pesq. Vet. Bras. 11(3/4):49-54.

Figueras J., Stein L., Diez V., Weil M.H. \& Shubin H. 1976. Relationship between pulmonary hemodynamics and arterial $\mathrm{Ph}$ and carbón dioxide tensión on critically ill patients. Chest 70:466-472.

Freda B.J., Tang W.H.W., Lente F.V., Peacock W.F. \& Francis G.S. 2002. Cardiac troponins in renal insufficiency: review and clinical implications. J. Am. Colleg. Cardiol. 40(12):2065-2071.

Godoy M.F., Braile D.M. \& Purini Neto J. 1998. A Troponina como marcador de injúria celular miocárdica. Arq. Bras. Cardiol. 71(4):629-633.

Jenkins C.P., Cardona D.M., Bowers J.N., Oliai B.R., Allan R.W. \& Normann S.J. 2010. The utility of C4d, C9, and troponin T immunohistochemistry in acute myocardial infarction. Arch. Pathol. Med. 134:256-263.

Kerr L.A. \& Kelch W.J. 1998. Pigweed (Amaranthus retroflexus) toxicosis in cattle. Vet. Human Toxicol. 40(4):216-218.

Lazzeri C., Bonizzoli M., Cianchi G., Gensini G.F. \& Peris A. 2008. Troponin I in the intensive care unit setting: from the heart to the heart. Intern. Emerg. Med. 3:9-16.

Lemos R.A., Barros C.S.L., Salles M.S., Barros S.S. \& Peixoto P.V. 1993. Intoxicação espontânea por Amaranthus spinosus (Amaranthaceae) em bovinos. Pesq. Vet. Bras. 13(1/2):25-34.
Martínez Díaz F., Rodríguez-Morlensín M., Pérez-Cárceles M.D., Noguera J., Luna A. \& Osuna E. 2005. Biochemical analysis and immunohistochemical determination of cardiac troponin for the postmortem diagnosis of myocardial damage. Histol. Histopathol. 20:475-481.

Martins C.S. 2009. Troponina: estrutura, fisiopatologia e importância clínica para além da isquemia miocárdica. Arq. Med. 23(6):221-240.

Nelson R.W. \& Couto C.G. 2006. Exames Diagnósticos do Sistema Cardiovascular: medicina interna de pequenos animais. Tradução da $3^{\mathfrak{a}}$ edição. Cap.2, 1324p.

Offerman S.R.R., Leers M.P.G., Suylen R.J.V., Nap M., Daemen M.J.A.P. \& Theunissen P.H.M.H. 2000. Evaluation of the membrane attack complex of complement for the detection of a recent myocardial infarction in man. J. Pathol. 191:48-53.

Osweiler G.D., Buck W.B. \& Bicknell E.J. 1969. Production of perirenal edema in swine with Amaranthus retroflexus. Am. J. Vet. Res. 30(4):557-566.

Özkan C., Altug N., Yüksen N., Kaya A. \& Akgül Y. 2011. Assessment of electrocardiographic findings, serum nitric oxide, cardiac troponins and some enzymes in calves with hyperkalemia related to neonatal diarrhea. Revue Méd. Vét. 162(4):171-176.

Pavarini S.P., Bandinelli M.B., Juffo G.D., Souza S.O., Driemeier D. \& Cruz C.E.F. 2012. Expressão diminuída de troponina cardíaca C associada com lesões cardíacas em bovinos intoxicados por Amorimia exotropica. Pesq. Vet. Bras. 32(10):1005-1008.

Pastor J.A., Castellanos A., Moleiro F. \& Myerburg R.J. 2001. Patterns of acute inferior wall myocardial infarction caused by hyperkalemia. J. Electrocardiol. 34(1):56-58.

Peixoto P.V., Brust L.A.C., Brito M.F., França T.N., Cunha B.R.M. \& Andrade G.B. 2003. Intoxicação natural por Amaranthus spinosus (Amaranthaceae) em ovinos no sudeste do Brasil. Pesq. Vet. Bras. 23(4):179-184.

Radostits O.M., Gay C.C., Blood D.C. \& Hinchcliff K.W. 2002. Doenças do sistema urinário, p.428-447. In: Ibid. (Eds), Clínica Veterinária: um tratado de doenças dos bovinos, ovinos, suínos, caprinos e equinos. 9ae ed. Guanabara Koogan, Rio de Janeiro.

Ribeiro-Silva A., Martin C. \& Rossi M.A. 2002. Is immunohistochemistry a useful tool in the postmortem recognition of myocardial hypoxia in human tissue with no morphological evidence of necrosis? Am. J. Forensic Med. Pathol. 23(1):72-77.

Ronco C., House A.A. \& Haapio M. 2008. Cardiorenal síndrome: refining the definition of a complex simbiosis gone wrong. J. Intensive Care Med. 34:957-962.

Salles M.S., Barros C.S.L., Lemos R.A. \& Pilati C. 1991. Perirenal edema associated with Amaranthus spp poisoning in Brazilian swine. Vet. Hum. Toxicol. 33(6):616-617.

Stuart B.P., Nicholson S.S. \& Smith J.B. 1975. Perirenal edema and toxic nephrosis in cattle, associated with ingestion of pigweed. J. Am. Med. Vet. Assoc. 167(10):949-950.

Takken A. \& Connor J.K. 1984. Some toxicological aspects of grain Amaranth for pigs, p.170-177. In: Seawright A.A., Hegarty M.P., James L.F. \& Keeler R.F. (Eds), Plant Toxicology Proc. Australia-USA Poisonous Plants Symposium, Queensland Poisonous Plant Committee, Brisbane, Australia.

Tizard I.R. 2014. Imunologia Veterinária: uma introdução. 9ạ ed. Elsevier, Rio de Janeiro. 568p.

Tokarnia C.H., Brito M.F., Barbosa J.D., Peixoto P.V. \& Döbereiner J. 2012. Plantas Tóxicas do Brasil para Animais de Produção. $2^{\underline{a}}$ ed. Helianthus, Rio de Janeiro. 586p.

Tunca R., Sozmen M., Erdogan H., Citil M., Uzlu E., Ozen H. \& Gokçe E. 2008. Determination of cardiac troponin I in the blood and the heart of calves with foot-and-mouth disease. J. Vet. Diagn. Invest. 20:598-605. 